\title{
Adsorption of Rhodamine-B and Congo red dye from Aqueous Solution using Activated Carbon: Kinetics, Isotherms, and Thermodynamics
}

\author{
M. Ilayaraja ${ }^{\mathrm{a}}$, N.P. Krishnan ${ }^{\mathrm{b}}$, R. Sayee Kannan ${ }^{\mathrm{a} *}$ \\ ${ }^{a} P G$ Research and Department of Chemistry, Thiagarajar college, Madurai-625 009,Tamil Nadu, India. \\ ${ }^{b}$ Department of Chemistry, K.L.N. College of engineering, Sivagangai-630 611,Tamil Nadu, India
}

\begin{abstract}
The present work aims to investigate the removal of dye Rhodamine- $B(R B)$ and Congo red (CR) dye from aqueous solutions by low cost bio-waste adsorbents, such as Maranta arundinacea activated carbon $(M A C)$ under various experimental conditions. The effect of dye concentrations, contact time, temperature and adsorbent dose on the removal of dyes was studied. The kinetic experimental data were fitted to pseudo-firstand pseudo-second - order model. Results imply that adsorption of $R B$ and $C R$ on these adsorbents nicely followed the second order kinetics model and maximum adsorption capacity was found to be $88.4 \mathrm{mg} / \mathrm{g}$ for $R B$ and $79.3 \mathrm{mg} / \mathrm{g}$ for $C R$, however it increase with increase in temperature for both dyes. Equilibrium adsorption was investigated by the Langmuir, Freundlich, Temkin, D-R and Jovanoic isotherms. The thermodynamics parameters of adsorption systems indicated spontaneous and exothermic process.
\end{abstract}

Key words: Activated carbon, Congo red, Isotherms, Kinetics, Rhodamine-B

\section{Introduction}

Dyes and pigments are widely applied in the textiles, paper, plastics, leather, food and cosmetic industries to color products. Organic dyes appear in many industrial effluents [1]. The wastewater contains large amount of dissolved dyestuffs and other products, such as dispersing agents, dye bath carrier, salts, emulsifiers, leveling agents and heavy metals [2]. The colored dye effluents are generally considered to be highly toxic to the aquatic system. Some dyes are reported to cause skin irritation, dermatitis, allergy and cancer in humans [3]. Congo red is a water soluble diazo dye with a solubility of $1 \mathrm{~g} / 30 \mathrm{~mL}$. It exists as brownish-red crystal and is stable in the air. It is an anionic acid dye, used in diagnosis of amyloidosis and in medicine as biological stain. It acts as an indicator by changing to red-brown color in alkaline medium and to blue color in acidic medium [4]. Apart from its various uses, the dye poses significant toxicity towards humans and animals. Both, short time or prolonged contacts of the dye with eyes and skin cause severe irritation. On ingestion, it produces gastrointestinal irritation with nausea, vomiting, and diarrhea. It is carcinogenic and prolonged use of the Congo red dye results into tumor formation amongst humans [5].

Rhodamine-B (RB) is one of the water soluble xanthenes class dyes, a basic red cationic dye which is a common water tracer fluorescent. It is often used in textile, cotton, wool, silk and food industries. It is potentially harmful to humans as it can cause eye burn, irritation to skin, gastrointestinal and the respiratory tracts. For these reasons, the treatment of dye effluents is essential prior to their discharge into the receiving water bodies [6].

Dye wastewater is usually treated by physical and chemical methods such as sonochemical degradation [7], photochemical degradation [8], electrochemical degradation [9], coagulation and flocculation [10], membrane separation [11], activated carbon adsorption [12] and oxidation or ozonation [13]. However, in developing countries, these methods are still too expensive to be used widely. Developing economical adsorbents to treat dyes wastewater has attracted a great interest in recent years. Recently, the application of low-cost adsorbents for the dyes and metal ions removal has been reviewed [14]. Among these, the adsorption method, using commercial activated carbons as adsorbent has been proved to be simple, more efficient and economically feasible technique for removal of dyes from wastewater.

Activated carbon is the most widely used adsorbent with great success due to its large surface area, micro porous structure and high adsorption capacity. However, its use is limited because of its high cost. This has led to search for cheaper substitutes [15]. Investigators have studied the feasibility of using low-cost substances, such as waste apricot [16], coconut shell [17], dairy sludge [18], bamboo grass treated with concentrated sulfuric acid [19], peat [20], bamboo [21], jack fruit peels [22], pistachio nut shells [23] and date stone and palm tree waste [24] as adsorbents for the removal of dyes and heavy metals from waste water.

In this work, Maranta arundinacea carbon were prepared using a chemical activation method and characterized by scanning electron microscope (SEM), FTIR, BET, EDS and XRD spectroscopy. The adsorption equilibrium, kinetics and thermodynamic studies have been investigated to observe the effects of 
various process parameters such as initial dye concentrations, contact time, dose and temperature on Rhodamine-B and Congo red dye removal.

\subsection{Dye solution preparation}

\section{Materials and Methods}

The dye Congo red [C.I name $=$ Direct Red 28, chemical formula weight $=696.65, \lambda \max -498 \mathrm{~nm}$ ] and Rhodamine-B [C.I. name $=$ Basic violet 10 , chemical formula weight $=479.02, \lambda$ max $-543 \mathrm{~nm}$ ] supplied by S.D fine Chemicals, Mumbai, India was used as such without further purification. An accurately weighed quantity of dye was dissolved in double distilled water to prepare the stock solutions.

\subsection{Adsorbent}

Maranta arundinacea (Aruruttukkilangu) was used as an adsorbent in the study. It was obtained from the local shop, Madurai (India) washed using tap water and finally with double distilled water to remove the suspended impurities, dust and soil and then dried in oven. About 500g of powdered Aruruttukkilangu was mixed with $100 \mathrm{ml}$ of con. Sulfuric acid and kept at room temperature for $24 \mathrm{hrs}$. Then it was dried in a hot air oven at $80^{\circ} \mathrm{C}$. The dried material was washed with distilled water to remove excess of acid. Charcoal was dried in $110^{\circ} \mathrm{C}$ for 12 hours to remove moisture and kept in air tightened bottle [25].

\subsection{Adsorption Experiments}

Batch mode adsorption studies were carried out by adding certain amount of adsorbent and 50ml of dye solutions of certain concentrations, dose, contact time and temperatures in a thermo stated water bath shaker at 200rpm. The samples were withdrawn from the shaker at predetermined time intervals and solutions were separated from the adsorbent by centrifugation at $4000 \mathrm{rpm}$ for $5 \mathrm{~min}$. To determine the residual dye concentration, the absorbance of the supernatant solution was measured before and after treatment with double beam spectrophotometer (JASCO V530 Spectrophotometer); Experiments were carried out twice and the concentrations given were average values. The initial dye concentrations in the test solution and the contact time were changed to investigate their effect on the adsorption kinetics. The $\mathrm{pH}$ of the dye solution was adjusted by using $\mathrm{NaOH}$ or $\mathrm{HCl}$ solution. The adsorption studies were carried out at different temperatures $(308,318$ and $328 \mathrm{~K})$. This is used to determine the effect of temperature on the thermodynamic parameters.

The amount of adsorption in batch experiments, $\mathrm{q}\left(\mathrm{mg} \mathrm{g}^{-1}\right)(1)$ and adsorption efficiency (2) were calculated as follows:

$\begin{array}{cl}\quad \mathbf{q}=\left(\mathbf{C}_{\mathbf{o}}-\mathbf{C}_{\mathbf{e}}\right) \mathbf{V} & / \mathbf{m} \\ \text { Where, } \mathrm{C}_{\mathrm{o}} & \text { is the initial concentration }\left(\mathrm{mg} \cdot \mathrm{L}^{-1}\right) \\ \mathrm{C}_{\mathrm{e}} & \text { is the equilibrium concentration }\left(\mathrm{mg} \cdot \mathrm{L}^{-1}\right) \\ \mathrm{V} & \text { is the volume of solution }(\mathrm{mL}) \\ \mathrm{M} & \text { is the mass of adsorbent }(\mathrm{g}) \\ \mathrm{q} & \text { is the amount adsorbed }\left(\mathrm{mg} \cdot \mathrm{g}^{-1}\right)\end{array}$

\subsection{Surface characteristic of the adsorbent}

Surface area and porous size distribution of MAC sample were measured by nitrogen adsorption analysis (Quantachrome V5.02). Crystal structure of sample was determined by performing X-ray diffraction (XRD) on SHIMADZU 6000 X-ray diffraction spectrometer. Surface morphologies were examined by a scanning electron microscope (SEM, JEOL (JSM 6390) with the working distance of $9.9 \mathrm{~mm}$ and an accelerating voltage of $30 \mathrm{keV}$. The SEM was equipped with an energy dispersion spectrometer (EDS) and it was used to perform the analysis of chemical constituents of the adsorbent. Infrared (IR) absorption spectroscopy spectra were measured at room temperature on a Fourier transform infrared (FTIR) spectroscopy (8400s SHIMADZU spectrometer) using the KBr pellet technique.

\subsection{Desorption experiments}

After adsorption experiments, the RB and CR loaded MAC was separated out by filtration using Whatman filter paper No. 42 and the filtrate was discarded. The RB and CR loaded MAC was given a gentle wash with double-distilled water to remove the non-adsorbed dyes if present. The dye loaded samples were agitated with distilled water by adjusting the initial $\mathrm{pH}$ from 2 to 12 for $180 \mathrm{~min}$. The desorbed dye solution was separated by centrifugation and analyzed as before. The percentage of desorption was calculated. The desorption ratio (E) was calculated as follows:

$$
\mathbf{E}(\%)=\mathbf{C}_{\mathbf{d}} \mathbf{V}_{\mathrm{d}} /\left(\mathrm{C}_{\mathbf{0}}-\mathrm{C}_{\mathrm{e}}\right) \times \mathbf{1 0 0}
$$

Where $\mathrm{E}$ is the desorption ratio, $\mathrm{C}_{\mathrm{d}}$ is the concentration of the solutes in the desorption solutions; $\mathrm{V}_{\mathrm{d}}$ is the volume of the desorption solution and $\mathrm{C}_{\mathrm{o}}, \mathrm{C}_{\mathrm{e}}$ and $\mathrm{V}$ are the same as defined in Eq. $1 \& 2$. 


\subsection{Characterization of the adsorbent}

\section{Results And Discussion}

The surface area of MAC was $22.43 \mathrm{~m}^{2} / \mathrm{g}$. The average pore radius of MAC was $6.30 \mathrm{~nm}$ and total pore volume was $0.13 \mathrm{~cm}^{3} / \mathrm{g}$ (Fig 1). The relative adsorption performance of different adsorbent is highly dependent on the internal pore structure of each material. With the increase of pore radius, more adsorbate is easier to be adsorbed. Therefore carbon activation offers some attractive advantages. It is not only able to increase the surface area and average pore radius but also reinforce the chemical strength of adsorbents in acidic medium.

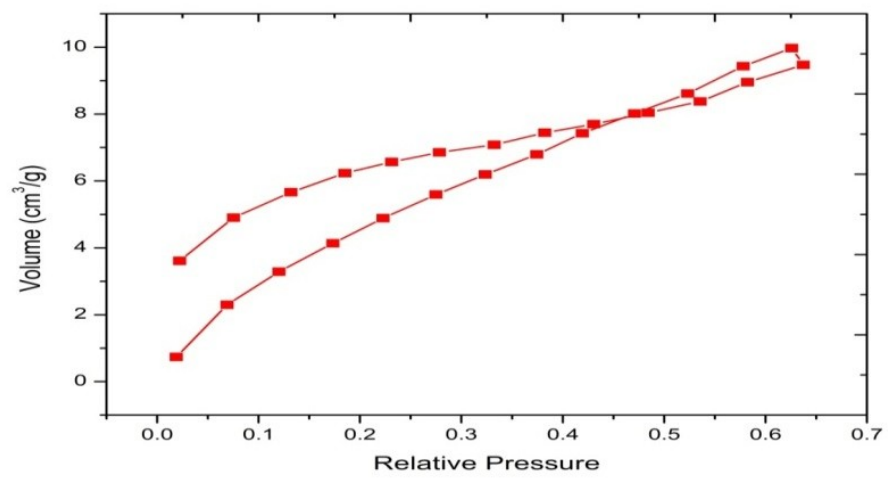

Fig. 1. $\mathrm{N}_{2}$ gas adsorption-desorption isotherm model for the MAC

FTIR spectra of the raw material, MAC, MAC-RB, MAC-CR are shown in Fig 2. FTIR data of raw material Fig. 2a, showed that characteristic band at 3766.9, 2929.8, 1645.2, 1419.6,1355.9, 1155.36 and 1004.9 $\mathrm{cm}^{-1}$ correspond to the free $\mathrm{OH}$, aliphatic $\mathrm{C}-\mathrm{H}$ stretching, $\mathrm{C}=\mathrm{C}, \mathrm{C}-\mathrm{H}$ bending vibrations, C-O-C stretching vibrations and secondary cyclic alcohols respectively.

The FTIR spectrum of chemical activated carbon (MAC) is exhibited in Fig 2b. The band at $3402.4 \mathrm{~cm}^{-}$ ${ }^{1}$ was assigned to $\mathrm{OH}$ stretching vibration. Two significant aspects of this band were observed. Firstly, it had been shifted to the lower wave number and secondly, it was significantly broaden. These findings apparently suggested that the $-\mathrm{OH}$ group in the activated carbon was not free but more likely cross-linked. The band at $2945.3 \mathrm{~cm}^{-1}$ in raw material higher wave number, but after modification was intensity lower, leading to the significant decrease of aliphaticity in the activated carbon. The new band observed at $1710.8 \mathrm{~cm}^{-1}$ is due to the $\mathrm{C}=\mathrm{O}$ stretching vibrations. After modification $\mathrm{C}=\mathrm{C}, \mathrm{C}-\mathrm{H}$ intensity were decreased from 1645.2 to 1616.3 and 1419.6 to 1365.6 respectively. The secondary cyclic alcohol group disappeared in activated carbon [26].

Fig. 2c indicated that mostly the bonded $\mathrm{OH}$ groups, $\mathrm{C}=\mathrm{C}$ stretching, $\mathrm{C}-\mathrm{H}$ bending vibrations and $\mathrm{C}-\mathrm{O}-$ $\mathrm{C}$ vibrations were involved in $\mathrm{RB}$ adsorption. There were clear band shifts and intensity decrease in Fig $2 \mathrm{c}$. These findings suggest that there is attachment of RB on the MAC.

The FTIR spectrum of MAC-CR (Fig. 2d) showed that characteristic band at 3415.9, 2949.1, 1710.8, 1614.4 and 1192.0 were correspond to $\mathrm{OH}, \mathrm{C}-\mathrm{H}$ stretching vibrations, $\mathrm{C}=\mathrm{O}$ and $\mathrm{C}=\mathrm{C}$ respectively. This figure shows that some peaks are shifted or disappeared. The change observed in the spectrum indicates the possible involvement of those functional groups on the surface of the MAC-CR adsorption.

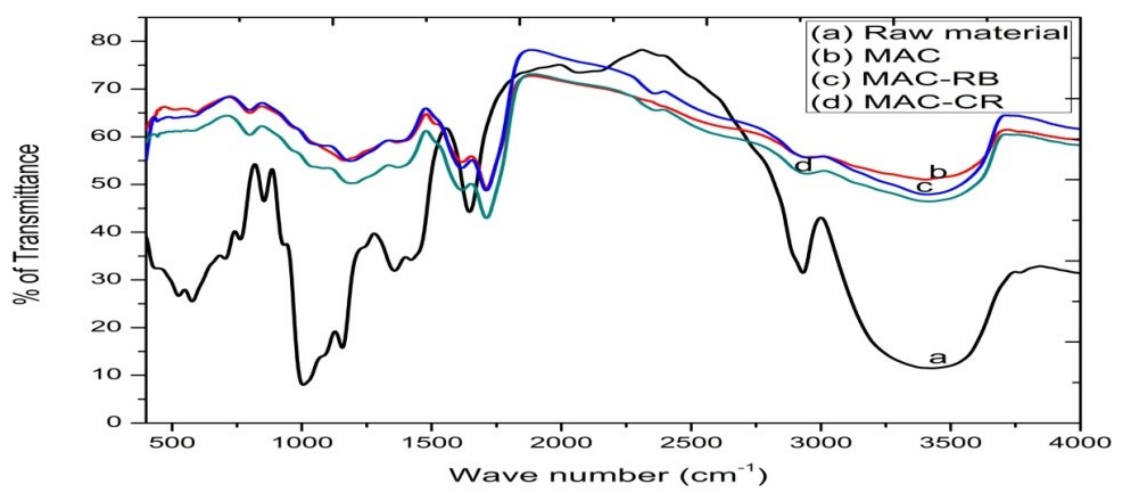

Fig. 2. FTIR spectra of (a) Raw material, (b) MAC, (c) MAC-RB, (d) MAC-CR

The XRD patterns as shown in Fig 3 were performed to analyze the crystalline nature. The characteristic $18^{\circ}-25^{\circ}$ peaks of MAC are discernible in carbon, the diffraction spectrum of MAC did not show any obvious crystalline peak at the scan range $10-90^{\circ}$ thereby indicating the amorphous phase of MAC. 


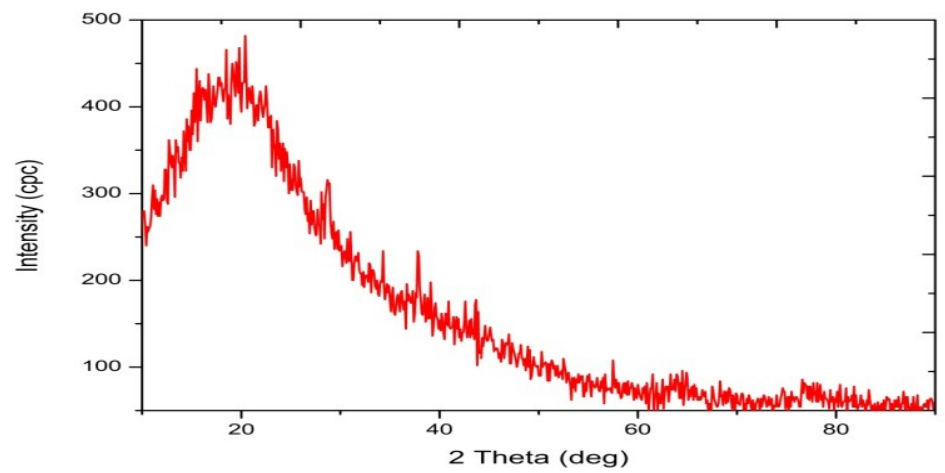

Fig. 3. XRD pattern of PCFR

The microstructure of MAC played an important role on its adsorption capacity (Fig.4). As illustrated in Fig 4a, MAC consisted mainly of compact or hollow spheres of different sizes and some irregular holes and pores were developed and found on the surfaces of the char due to the sudden burst of carbon. It was also seen in the micrograph that some of the smaller size particles adhered on bigger size particles. It illustrates a number of pores on the surface of the MAC revealing the potential adsorption power. The surface of RB and CR loadedMAC, however clearly shows that the surface of MAC is covered with both dye molecules and the same is observed in Fig. $4 \mathrm{~b}$ and $4 \mathrm{c}$ [27].
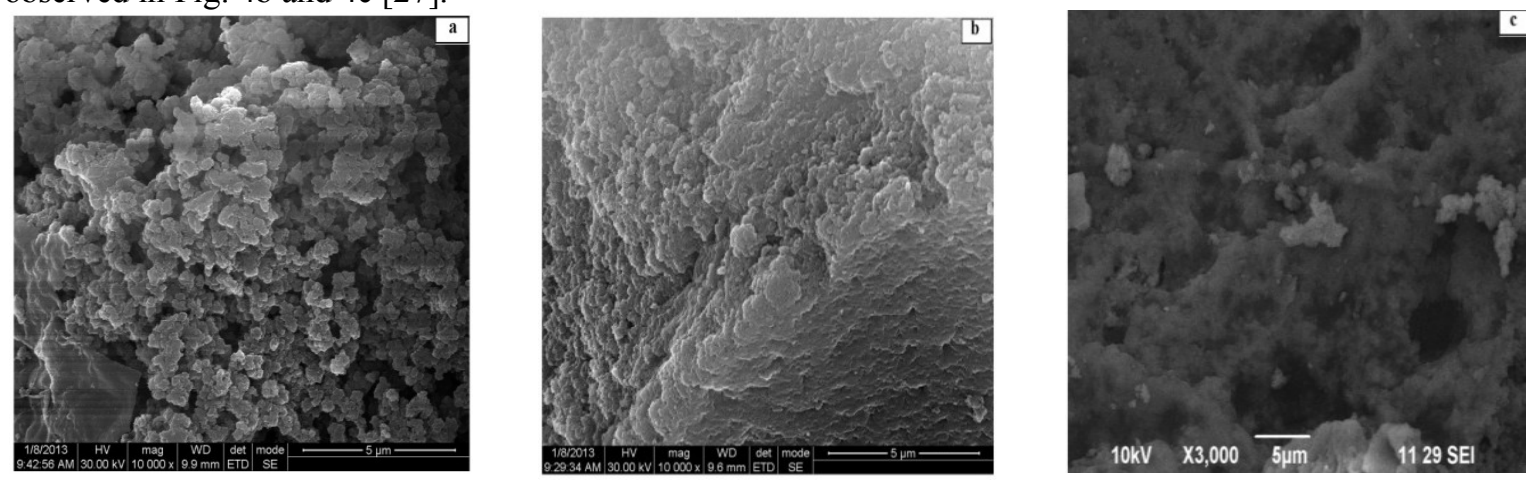

Fig. 4. The SEM images of (a) MAC, (b) MAC-RB, (c) MAC-CR

Further confirmation of the adsorption of RB and CR on MAC carbon was done by energy dispersive $\mathrm{X}$-ray analysis (EDX). Fig. 5a for the unloaded MAC shows two characteristic signals for $\mathrm{C}$ and $\mathrm{O}$ composition as $70.87 \%$ and $19.33 \%$ respectively. The EDS spectrum (Fig $5 \mathrm{~b}$ ) of after adsorption of MAC-CR presented same element but $\mathrm{C}$ atomic percentage was decreased from 70.87 to $70.41 \%$ and oxygen percentage was increased from 19.33 to $25.10 \%$. It provided an evidence for CR adsorption onto MAC surface. Fig 5c shows three components $\mathrm{C}$ and $\mathrm{H}$ and $\mathrm{S}$ values for the MAC-RB adsorption composition as $68.79 \%, 31.10 \%$ and $0.12 \%$ respectively. By comparing Fig $5 \mathrm{a} \& 5 \mathrm{c}$, it is clear that $\mathrm{C}$ atomic percentage was decreased, due to adsorption of both RB and CR dye onto MAC.
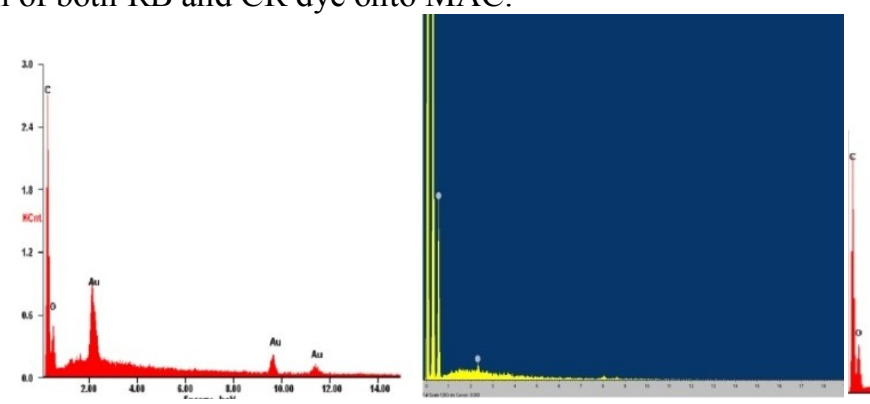

Fig. 5. Energy dispersive spectra of (a) MAC, (b) MAC-RB, (c) MAC-CR

\subsection{Effect of initial dye concentrations}

In order to determine the optimum initial concentration of the target dye, its value was varied (for both dye under study) in the range $30-120 \mathrm{mg} / \mathrm{L}$, while keeping the temperature, adsorbent mass and the contact time constant at $298 \mathrm{~K}, 0.200 \mathrm{~g}$ and $40 \mathrm{~min}$ respectively. The effect of initial concentration on the removal of CR and RB by the adsorbent is indicated in Table 1. It is evident from the table that percentage of CR and RB removal decreases with increase in dye concentrations; however actual amount of the dye adsorbed is increased. This is 
due to increase in dyes concentration, surface area and active sites of the adsorbent were saturated and hence percentage removal decreases.

Table.1. Effect of initial concentrations of RB and CR

\begin{tabular}{|c|c|c|c|c|c|c|c|c|c|c|c|c|}
\hline \multirow{2}{*}{ Concentrations } & \multicolumn{6}{|c|}{ Adsorption efficiency (\%) } & \multicolumn{6}{|c|}{ Amount of adsorbed, q (mg/g) } \\
\hline & 30 & 50 & 70 & 90 & 100 & 120 & 30 & 50 & 70 & 90 & 100 & 120 \\
\hline $\mathrm{RB}$ & 86.9 & 79.1 & 70.6 & 60.7 & 52.8 & 46 & 250 & 237 & 222 & 197 & 182 & 160 \\
\hline $\mathrm{CR}$ & 78.2 & 74.1 & 68.2 & 62.3 & 48.5 & 38.1 & 225 & 222 & 215 & 202 & 167 & 132 \\
\hline
\end{tabular}

\subsection{Effect of contact time}

In order to determine the optimum contact time, its value was varied in the range of 20-100 min in a series of experiments in which the initial target dye concentration, the temperature and adsorbent amount were kept constant at $30 \mathrm{mg} / \mathrm{L}, 298 \mathrm{~K}$ and $0.600 \mathrm{~g}$ respectively. The effect of contact time on the removal of CR and $\mathrm{RB}$ by the adsorbent is indicated in Table 2 . It is indicated that uptake of the dye is rapid in the beginning and then it becomes constant. The adsorption curves are single, smooth, and continuous leading to saturation and indicate the possible monolayer coverage on the surface of adsorbents by the molecules.

Table.2. Effect of contact time

\begin{tabular}{|c|c|c|c|c|c|c|c|c|c|c|}
\hline \multirow{2}{*}{$\begin{array}{l}\text { Contact time } \\
(\mathrm{min})\end{array}$} & \multicolumn{5}{|c|}{ Adsorption efficiency (\%) } & \multicolumn{5}{|c|}{ Amount of adsorbed, $\mathrm{q}(\mathrm{mg} / \mathrm{g})$} \\
\hline & 20 & 40 & 60 & 80 & 100 & 20 & 40 & 60 & 80 & 100 \\
\hline $\mathrm{RB}$ & 88.6 & 91.3 & 91.3 & 91.3 & 91.3 & 85 & 87.5 & 87.5 & 87.5 & 87.5 \\
\hline CR & 80.9 & 82.6 & 82.6 & 82.6 & 82.6 & 77.5 & 79.1 & 79.1 & 79.1 & 79.1 \\
\hline
\end{tabular}

\subsection{Effect of adsorbent mass}

In these experiments, target dye solutions with a concentration of $30 \mathrm{mg} / \mathrm{L}$ were placed in contact with various amounts of adsorbent $(0.200-1.000 \mathrm{~g})$ for $40 \mathrm{~min}$ at $298 \mathrm{~K}$. The results are presented in Table 3 . The adsorption of both dyes increased with increasing the sorbent mass due to the availability of higher number of adsorbing active sites.

Table.3. Effect of adsorbent dose

\begin{tabular}{|c|c|c|c|c|c|c|c|c|c|c|}
\hline \multirow[b]{2}{*}{ Dose $(g)$} & \multicolumn{5}{|c|}{ Adsorption efficiency (\%) } & \multicolumn{5}{|c|}{ Amount of adsorbed, $\mathrm{q}(\mathrm{mg} / \mathrm{g})$} \\
\hline & 0.200 & 0.400 & 0.600 & 0.800 & 1.000 & 0.200 & 0.400 & 0.600 & 0.800 & 1.000 \\
\hline RB & 88.6 & 90.4 & 92.1 & 92.1 & 92.1 & 255 & 130 & 88.3 & 66.2 & 53 \\
\hline $\mathrm{CR}$ & 78.2 & 80.0 & 82.6 & 82.6 & 82.6 & 225 & 115 & 79.1 & 59.3 & 47.5 \\
\hline
\end{tabular}

\subsection{Adsorption isotherms}

The experimental data collected at $298 \mathrm{~K}$ and initial concentration of $30 \mathrm{mg} / \mathrm{L}$ were fitted on the standard models used in waste water treatment application: Langmuir, Freundlich, Temkin, D-R and Jovanoic isotherm respectively.

The Langmuir model assumes that the solid surface carries a limited number of sites that are characterized by equal energy of adsorption, independent of the degree of coverage and thus indicating a monolayer adsorption. The linearized form of the Langmuir equation is described by Eq. (4) [28].

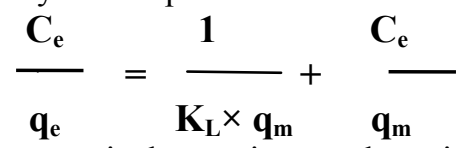

Where, $\mathrm{q}_{\mathrm{m}}$ is the maximum adsorption capacity, $\mathrm{K}_{\mathrm{L}}$ is the Langmuir bonding energy coefficient. The $\mathrm{K}_{\mathrm{L}}$ and $\mathrm{q}_{\mathrm{m}}$ can be calculated from the intercept and slope of the linear plot of $\mathrm{C}_{\mathrm{e}} / \mathrm{q}_{\mathrm{e}}$ against $\mathrm{C}_{\mathrm{e}}$ as shown in Fig 6

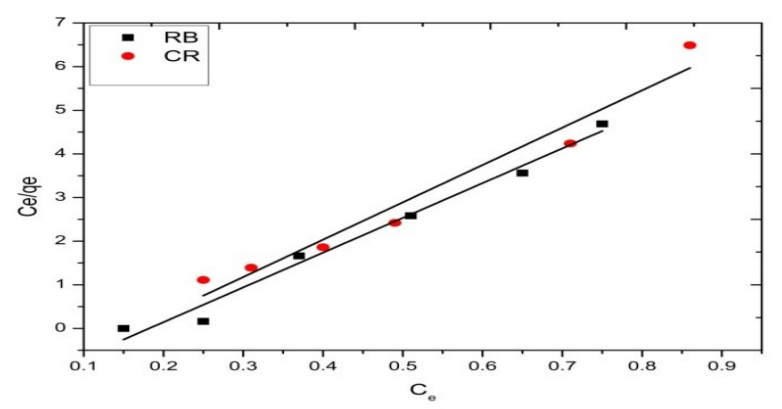

Fig. 6. Langmuir isotherm plots for the adsorption of RB and CR onto MAC 
It is obvious that the Langmuir adsorption isotherm is more suitable to describe the adsorption equilibrium $\left(\mathrm{R}^{2}>\right.$ 0.979). Therefore, monolayer coverage of RB on MAC particles is assumed with the maximum adsorption capacity of $12.55 \mathrm{mg} \mathrm{g}^{-1}$.

The basic characteristics for the Langmuir isotherm can be expressed in terms of the dimensionless constant separation factor for equilibrium parameter; $R_{L}[29]$ is calculated using the following equation.

$$
\mathbf{R}_{\mathrm{L}}=\mathbf{1} / \mathbf{1}+\mathrm{K}_{\mathrm{L}} \mathbf{C}_{\mathbf{o}}
$$

Where $K_{L}\left(\mathrm{~L}_{\mathrm{mg}} \mathrm{mg}^{-1}\right)$ is the Langmuir constant related to the energy of adsorption and $\mathrm{C}_{\mathrm{o}}\left(\mathrm{mg} \cdot \mathrm{L}^{-1}\right)$ is the initial concentration of both $\mathrm{RB}$ and $\mathrm{CR}$ dyes. The $\mathrm{R}_{\mathrm{L}}$ value indicates the type of the isotherm as either unfavorable $\left(R_{L}>1\right)$, linear $\left(R_{L}=1\right)$, favorable $\left(0<R_{L}<1\right)$ or irreversible $\left(R_{L}=0\right)$. It is clear from Table 4 that all $R_{L}$ values lies between 0 and 1 indicating the favorable sorption of both RB and CR dye by the MAC.

Table 4. Separation factor

\begin{tabular}{ccccccc}
\hline \multirow{2}{*}{ Dyes } & \multicolumn{7}{c}{$\mathrm{R}_{\mathrm{L}}$ values } \\
\cline { 2 - 7 } & 10 & 30 & 50 & 70 & 90 & 100 \\
\hline RB & 0.136 & 0.131 & 0.126 & 0.122 & 0.116 & 0.115 \\
CR & 0.123 & 0.118 & 0.113 & 0.124 & 0.105 & 0.104 \\
\hline
\end{tabular}

The Freundlich isotherms is an empirical equation and is one of the most widely used isotherms for the description of multi-site adsorption. The linear form as follows:

$\log \mathrm{q}_{\mathrm{e}}=\log \mathrm{K}_{\mathrm{F}}+1 / \mathrm{n} \log \mathrm{C}_{\mathrm{e}}$

Where $\mathrm{K}_{\mathrm{F}}$ and $\mathrm{n}$ are the Freundlich isotherm constants indicating the adsorption capacity and adsorption intensity respectively [30]. The $\mathrm{K}_{\mathrm{F}}$ and $\mathrm{n}$ can be calculated from the intercept and slope of the linear plot of log $\mathrm{q}_{\mathrm{e}}$ against $\log \mathrm{C}_{\mathrm{e}}$. The value of $\mathrm{n}>1$ (3.819 and 2.464) indicates favorable and heterogeneous adsorption of $\mathrm{RB}$ and $\mathrm{CR}$ onto MAC. Both the dyes did not follow the Freundlich isotherm as closely as the Langmuir isotherm.

To study the heat of adsorption and adsorbate - adsorbent interaction on the adsorbent surface, the Temkin isotherm is applied [31]. Equation 7, shows the linearized form of this isotherm

$$
\mathbf{q}_{\mathrm{e}}=\mathrm{B}_{1} \ln \mathrm{K}_{\mathrm{T}}+\mathrm{B}_{1} \ln \mathbf{C}_{\mathrm{e}}
$$

Where $\mathrm{B}_{1}$ is the Temkin adsorption constant and $\mathrm{K}_{\mathrm{T}}$ is the equilibrium binding constant (L.mol ${ }^{-1}$ )

The linearized D-R equation [32] may be written as

$$
\ln q_{\mathrm{e}}=\ln \mathbf{q}_{\mathrm{m}}-\boldsymbol{\beta} \varepsilon^{2}
$$

Where $\beta$ a constant related to the adsorption energy $\left(\mathrm{mol}^{2} / \mathrm{kJ}^{2}\right), \mathrm{q}_{\mathrm{m}}$ is a constant that indicates the sorption degree characterizing the sorbent $(\mathrm{mg} / \mathrm{g})$ and $\varepsilon$ is the Polanyi potential shown in Eq.8:

$$
\varepsilon=R T \ln \left(1+1 / C_{e}\right)
$$

Where $\mathrm{T}$ is the absolute temperature $(\mathrm{K})$ and $\mathrm{R}$ is the ideal gas constant $(\mathrm{R}=8.314 \mathrm{~J} / \mathrm{mol} \mathrm{K})$. By plotting $\ln \mathrm{q}_{\mathrm{e}} \mathrm{vs}$ $\varepsilon^{2}$ (Fig 7), it is possible to determine the value of $\beta$ from the slope and the value of $\mathrm{q}_{\mathrm{m}}$ from the intercept, which is $\ln \mathrm{q}_{\mathrm{m}}$.

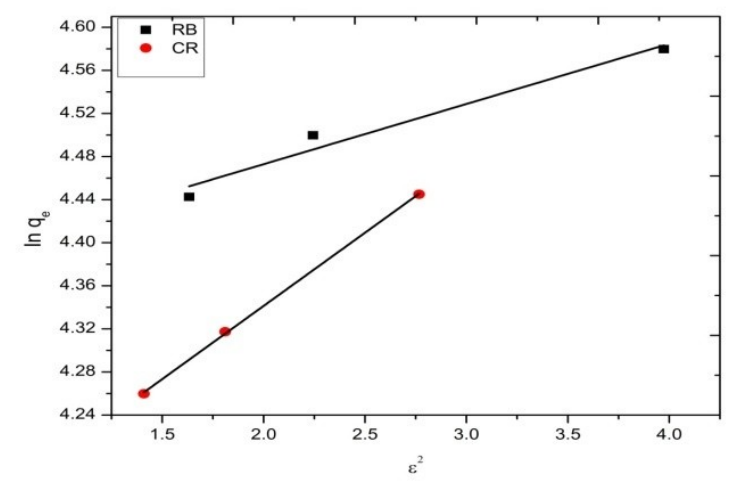

Fig. 7. D-R isotherm plots for the adsorption of RB and CR onto MAC

The mean free energy $\mathrm{E}(\mathrm{kJ} / \mathrm{mol})$ of sorption can be estimated by using $\beta$ values as expressed in the following equation [33].

$$
\mathrm{E}=1 /(2 \beta)^{1 / 2}
$$

The magnitude of $\mathrm{E}$ may characterize the type of the adsorption as chemical ion exchange $(\mathrm{E}=8-16 \mathrm{~kJ} / \mathrm{mol})$, or physical adsorption $(\mathrm{E}<8 \mathrm{~kJ} / \mathrm{mol})$. The mean free energy of adsorption for the present study was found to be 3.015 and $1.924 \mathrm{~kJ} / \mathrm{mol}$ for $\mathrm{RB}$ and $\mathrm{CR}$ respectively. This implies that, the adsorption of both $\mathrm{RB}$ and $\mathrm{CR}$ on MAC may be considered as physical adsorption process. 
The Jovanoic isotherm [34], which is based on the same assumptions of the Langmuir isotherm, also considers the possibility of some mechanical contacts between the adsorbing and desorbing molecules on the homogeneous surface and can be represented in a linear form as follows:

$$
\ln \mathbf{q}_{\mathrm{e}}=\ln \mathbf{q}_{\mathrm{m}}+\mathrm{K}_{\mathrm{J}} \mathbf{C}_{\mathrm{e}}
$$

Where, $\mathrm{q}_{\mathrm{m}}$ is the maximum amount adsorbed (in $\mathrm{mg} / \mathrm{g}$ ) and $\mathrm{K}_{\mathrm{J}}$ (in $\mathrm{L} / \mathrm{mg}$ ) is the constant related to the energy of adsorption. The $\mathrm{q}_{\mathrm{m}}$ and $\mathrm{K}_{\mathrm{J}}$ can be calculated from the intercept and slope of the linear plot of $\ln \mathrm{q}_{\mathrm{e}}$ against $\mathrm{C}_{\mathrm{e}}$ (Fig 8).

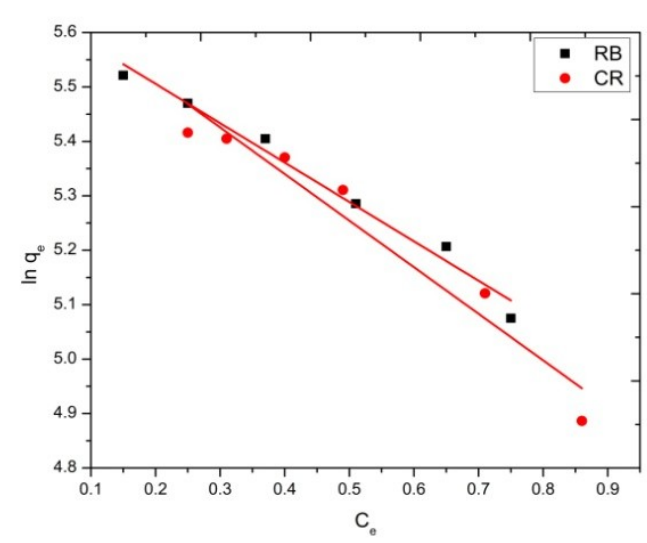

Fig. 7. Jovanoic isotherm plots for the adsorption of RB and CR onto MAC

To understand the adsorption equilibrium behavior, five isotherms, namely Langmuir, Freundlich, Temkin, D-R and Jovanoic isotherm models were tested, and the Table 5 summarizes the isotherm parameter values. The best fitted models are selected on the basis of correlation coefficient D-R, Jovanoic and Langmuir isotherm model. The D-R isotherm model was well described in CR than RB dye onto MAC. The maximum amount adsorbed was 11.72 and $22.96 \mathrm{mg} / \mathrm{g}$ for $\mathrm{CR}$ and RB respectively. The Jovanoic isotherm model was well described in RB onto MAC. The maximum amount adsorbed was $5.650 \mathrm{mg} / \mathrm{g}$ for RB. The Langmuir isotherm was the best fit model for the adsorption of RB with maximum adsorption capacity of $12.55 \mathrm{mg}$. $\mathrm{g}^{-1}$.

Table.5. Different adsorption isotherm model parameters for the adsorption of RB and CR on MAC

\begin{tabular}{llll}
\hline \multicolumn{1}{c}{ Mathematical models } & parameters & $\mathrm{RB}$ & $\mathrm{CR}$ \\
\hline Langmuir isotherm & $\mathrm{R}^{2}$ & 0.979 & 0.953 \\
& $\mathrm{~K}_{\mathrm{L}}$ & 55.01 & 61.70 \\
& $\mathrm{q}_{\mathrm{m}}(\mathrm{mg} / \mathrm{g})$ & 12.55 & 11.68 \\
Freundlich isotherm & & & \\
& $\mathrm{R}^{2}$ & 0.865 & 0.814 \\
& $\mathrm{~K}_{\mathrm{F}} \times 10^{3}$ & 120.19 & 86.11 \\
& $\mathrm{n}$ & 3.819 & 2.464 \\
Temkin isotherm & & 0.907 & 0.861 \\
& $\mathrm{R}^{2}$ & 54.02 & 72.97 \\
& $\mathrm{~B}_{1}$ & 157.2 & 137.2 \\
D-R isotherm & $\mathrm{K}_{\mathrm{T}}$ & & \\
& & 0.940 & 0.999 \\
& $\mathrm{R}^{2}$ & 0.055 & 0.135 \\
& $\beta$ & 22.96 & 11.72 \\
Jovanoic isotherm & $\mathrm{q}_{\mathrm{m}}(\mathrm{mg} / \mathrm{g})$ & 3.015 & 1.924 \\
& $\mathrm{E} \mathrm{kJ} / \mathrm{mol}$ & & \\
& $\mathrm{R}^{2}$ & 0.981 & 0.946 \\
& $\mathrm{~K}_{\mathrm{J}}(\mathrm{L} / \mathrm{mg})$ & 0.723 & 0.855 \\
& $\mathrm{q}_{\mathrm{m}}(\mathrm{mg} / \mathrm{g})$ & 5.650 & 5.682 \\
\hline
\end{tabular}




\subsection{Kinetic Studies.}

Kinetic models have been proposed to determine the mechanism of the adsorption process which provides useful data to improve the efficiency of the adsorption and feasibility of process scale-up [35]. The rate constants were calculated by using pseudo-first-order and pseudo-second-order kinetic models and the rate controlling step was determined by intra-particle diffusion model.

\subsubsection{Pseudo-first-order model}

The Lagergren pseudo first-order model is given by the following equation [36]

$\ln \left(q_{e}-q_{t}\right)=\ln q_{e}-k_{1} t$

Where $\mathrm{q}_{\mathrm{e}}$ and $\mathrm{q}_{\mathrm{t}}$ are the sorption capacities at equilibrium and time $\mathrm{t}$ respectively (mol.g $\mathrm{g}^{-1}$ ), and $\mathrm{k}_{1}$ represents the rate constant of the pseudo first- order kinetic model $\left(\mathrm{min}^{-1}\right)$. The data obtained for sorption of CR and RB on activated carbon based on the pseudo first - order kinetic model showed that the adsorption kinetics were not in a good agreement with the pseudo first - order model. The inapplicability of the Lagergren model to describe the kinetics of RB adsorption was also reported by Lata et al [37].

\subsubsection{Pseudo-second-order model}

The linearized form of the pseudo second - order kinetic model is represented as follows:

$$
\frac{t}{q_{t}}=\frac{1}{k_{2} q_{e}{ }^{2}}+\frac{t}{q_{e}}
$$

Where $\mathrm{k}_{2}(\mathrm{~g} / \mathrm{mg} / \mathrm{min})$ is the second-order rate constant of adsorption. The plot of $t / \mathrm{q}_{\mathrm{t}}$ versus $\mathrm{t}$ shows a linear relationship. Values of $\mathrm{k}_{2}$ and equilibrium adsorption capacity $\mathrm{q}_{\mathrm{e}}$ were calculated from the intercept and slope of the plot shown in Fig 9.

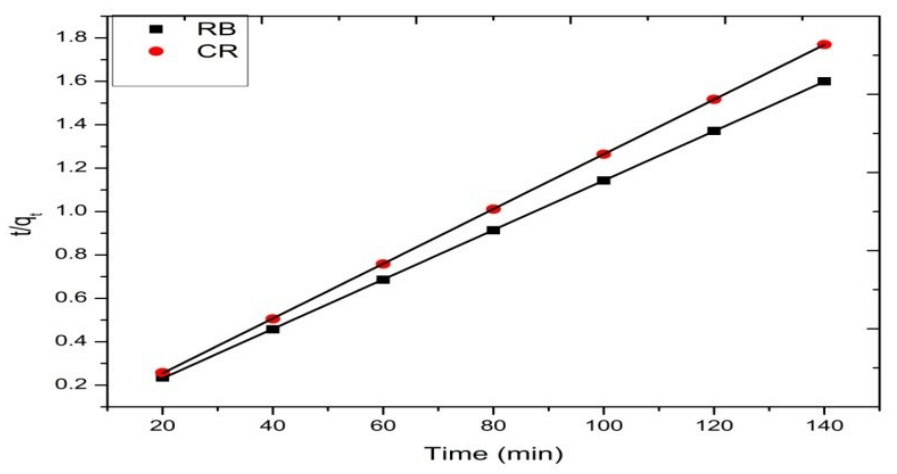

Fig. 9. Pseudo-second-order kinetic model plots of RB and CR onto MAC

\subsubsection{Intra-particle diffusion model}

For a solid-liquid adsorption process, the solute transfer is usually characterized by external mass transfer or intra-particle diffusion or both. The intra-particle diffusion model proposed by Weber and Morris [38] was used to identify the mechanism involved in the adsorption process:

$$
\mathbf{q}_{\mathbf{t}}=\mathbf{k}_{\mathrm{id}} \mathbf{t}^{\mathbf{0 . 5}}+\mathbf{C}
$$

Where $\mathrm{k}_{\mathrm{id}}\left(\mathrm{mg} \mathrm{g}^{-1} \mathrm{~min}^{-0.5}\right)$ is the rate constant of the intra-particle diffusion model and $\mathrm{C}\left(\mathrm{mg} \mathrm{g}^{-1}\right)$ reflects the boundary layer effect. The $\mathrm{k}_{\mathrm{id}}$ and $\mathrm{C}$ can be determined from the slope and intercept of the linear plot of $\mathrm{q}_{\mathrm{t}}$ against $\mathrm{t}^{0.5}$.

Table 5, summarizes the parameters and coefficients of the pseudo first - order and pseudo second order kinetic and intra-particle diffusion model. The results show that the correlation coefficients $\left(\mathrm{R}^{2}\right)$ for the pseudo-second-order adsorption model has high value $(>0.999)$ for adsorbent. These facts demonstrate that the adsorption data are well represented by pseudo-second-order kinetic model shown in Fig 9, indicating that the rate-limiting step might be due to chemical adsorption, high specific surface area and the absence of internal diffusion resistance. It was likely that the adsorption behavior may involve valence forces by sharing of electrons between anions and bio-adsorbents. The pseudo-second-order adsorption has also reported for many adsorbents such as natural kaolinite [39]. 
Table.6. Kinetic and Thermodynamic parameters for the adsorption of RB and CR on MAC

\begin{tabular}{llll}
\hline \multicolumn{1}{c}{ Mathematical models } & parameters & $\mathrm{RB}$ & $\mathrm{CR}$ \\
\hline First-order kinetics & $\mathrm{R}^{2}\left(\mathrm{kin}^{-1}\right)$ & 0.145 & 0.199 \\
& $\mathrm{k}_{1}\left(\mathrm{~m}_{\mathrm{e}}(\mathrm{mg} / \mathrm{g})\right.$ & 0.003 & 6.296 \\
& & 4.421 & 1.096 \\
Second-order kinetics & $\mathrm{R}^{2}$ & 0.999 & 0.999 \\
& $\mathrm{k}_{2} \mathrm{~g} / \mathrm{mg} / \mathrm{min}$ & 3.054 & 4.345 \\
& $\mathrm{q}_{\mathrm{e}}(\mathrm{mg} / \mathrm{g})$ & 88.49 & 79.36 \\
Intra-particle diffusion & $\mathrm{R}^{2}$ & 0.471 & 0.471 \\
& $\mathrm{k}_{\text {id }} \mathrm{g} / \mathrm{mg} / \mathrm{min}^{1 / 2}$ & 0.255 & 0.399 \\
& $\mathrm{C}(\mathrm{mg} / \mathrm{g})$ & 76.86 & 84.00 \\
Thermodynamic study & $\mathrm{R}^{2}$ & 0.902 & 0.670 \\
& $\Delta \mathrm{H}^{\circ} \mathrm{J} / \mathrm{mol}$ & -41.71 & -74.63 \\
& $\Delta \mathrm{S}^{\circ} \mathrm{J} / \mathrm{mol} \mathrm{K}$ & -146.2 & -249.1 \\
& $-\Delta \mathrm{G}^{\circ} \times 10^{2} \mathrm{~kJ} / \mathrm{mol}$ & & \\
& $308 \mathrm{~K} \mathrm{~kJ} / \mathrm{mol}$ & 34.9 & 26.6 \\
& $318 \mathrm{~K}$ & 44.5 & 33.8 \\
& $328 \mathrm{~K}$ & 64.4 & 77.2 \\
& & & \\
\hline
\end{tabular}

\subsection{Effect of temperature and thermodynamic data}

The effect of temperature on the adsorption of CR and RB on MAC particles has been studied in the range of $308-328 \mathrm{~K}$, keeping all the other parameters constant at their optimum value (Adsorbent mass- $0.600 \mathrm{~g}$, target dye concentration- $30 \mathrm{~g} . \mathrm{L}^{-1}$, contact time- $60 \mathrm{~min}$ ). The results (Table 7) show that the adsorption of both dyes is favored by an increase in temperature.

Table.7. Effect of Temperature

\begin{tabular}{lllllll}
\hline \multirow{2}{*}{ Metal ions } & \multicolumn{5}{c}{ Adsorption Efficiency (\%) } & \multicolumn{4}{c}{ Amount of adsorbed, q (mg/g) } \\
\cline { 2 - 7 } & $308 \mathrm{~K}$ & $318 \mathrm{~K}$ & $328 \mathrm{~K}$ & $308 \mathrm{~K}$ & $318 \mathrm{~K}$ & $328 \mathrm{~K}$ \\
\hline RB & 79.6 & 84.6 & 91.4 & 85 & 90 & 97.5 \\
CR & 73.9 & 78.2 & 85.2 & 70.8 & 75.0 & 81.6 \\
\hline
\end{tabular}

Thermodynamic parameters, such as changes in Gibbs free energy $\left(\Delta \mathrm{G}^{\circ}\right)$, enthalpy $\left(\Delta \mathrm{H}^{\circ}\right)$ and entropy $\left(\Delta \mathrm{S}^{\circ}\right)$ are the actual indicators for practical applications. Adsorption thermodynamics was evaluated with respect to different temperatures $(308,318$ and $328 \mathrm{~K})$. The thermodynamic parameters were calculated by the following equations:

$$
K_{c}=\frac{C_{e}}{\left(C_{i}-C_{e}\right)}
$$

Where $\mathrm{K}_{\mathrm{c}}$ is the equilibrium constants, $\mathrm{C}_{\mathrm{e}}$ is the concentration of solute adsorbed on the resin at equilibrium, $\mathrm{mg} / \mathrm{L}$ and $\mathrm{C}_{\mathrm{i}}$ is the initial ion concentration.

$$
\Delta \mathbf{G}^{\circ}=-\mathbf{R T} \ln \mathbf{K}_{\mathrm{c}}
$$

The change in enthalpy $\left(\Delta \mathrm{H}^{\circ}\right)$ and entropy $\left(\Delta \mathrm{S}^{\circ}\right)$ was determined from the slope and intercept, respectively of the $\ln \mathrm{K}_{\mathrm{c}}$ vs $1 / \mathrm{T}$ plot (Fig 10), according to the following equation:

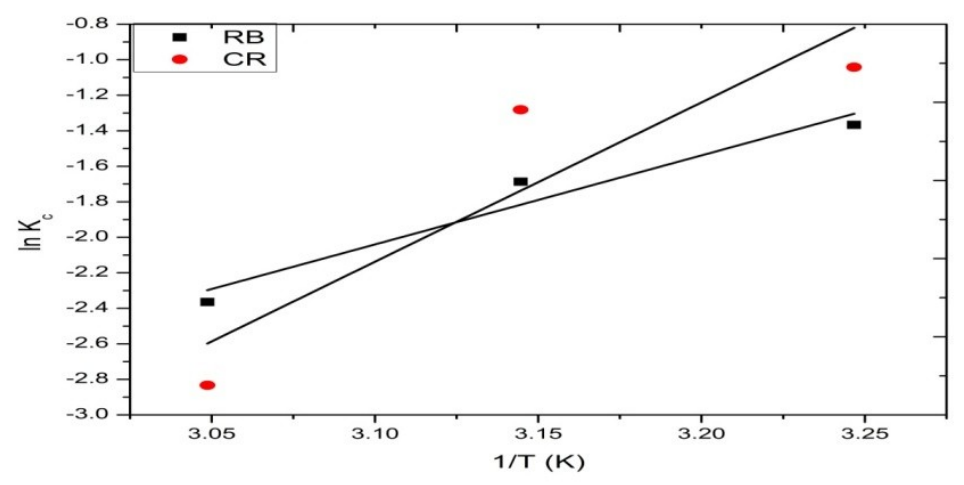

Fig. 10. Plot of $\ln \mathrm{K}_{\mathrm{c}}$ as a function of reciprocal of temperature (1/T) for the adsorption of RB and CR $\Delta \mathbf{S}^{\circ} \Delta \mathbf{H}^{\circ}$

$\ln \mathbf{K}_{\mathrm{c}}=--$ 


\section{R RT}

Where $\mathrm{R}$ is the gas constant $(8.314 \mathrm{~J} / \mathrm{mol} \mathrm{K}$ ), $\mathrm{T}$ is the temperature (in $\mathrm{K}$ ). The estimated thermodynamic parameters are presented in Table 5 . The negative $\Delta \mathrm{H}^{\circ}$ and $\Delta \mathrm{S}^{\circ}$ values mean a chemical exothermic process accompanied by a lowering in the entropy due to the adsorption of both dyes on the MAC carbon surface. The negative value of $\Delta \mathrm{G}^{\circ}$ at all temperatures indicated the spontaneous nature of the adsorption of both dyes on the MAC adsorbent.

\subsection{Desorption studies}

Desorption studies helps to elucidate one mechanism of adsorption and recovery of the adsorbate and adsorbent. The regeneration of the adsorbent may make the treatment process economical. The trend in the desorption process at different $\mathrm{pH}$ values is just converse to that of the adsorption process in the $\mathrm{pH}$ effect. The percent desorption of $\mathrm{RB}$ increase from 13 to 81 with increase in $\mathrm{pH}$ of desorbing solution from 2.0 to 10.0. The percent desorption is decreased from 44 to 35 with increase $\mathrm{pH}$ from 2 to 10 for CR. This indicates that the both $\mathrm{RB}$ and $\mathrm{CR}$ dyes adsorption is mainly due to ion exchange and physical adsorption [40].

\section{Conclusions}

In this study, batch adsorption experiments for the removal of RB and CR dyes from aqueous solutions had been carried out using MAC adsorbents. This adsorbent may be viewed as useful material while considering the economic aspects of wastewater treatment. The obtained results can be summarized as follows:

(1) The optimum dye concentration for the both dye was found to be $30 \mathrm{mg} / \mathrm{L}$ for MAC.

(2) Increase in adsorbent dosage leads to percentage increase in RB and CR dye removal due to enhancement of adsorption sites. Maximum uptake was obtained at adsorbent dosage of $0.6 \mathrm{~g}$ for the both dyes.

(3) The equilibrium time for the adsorption of RB and CR dye from aqueous solution were varied from 20 to $140 \mathrm{~min}$. The optimum time removal was found to be $40 \mathrm{~min}$ for both dyes.

(4) The statistical parameter indicated that the removal of both dyes onto natural adsorbent follow pseudo second-order model.

(5) The adsorption of RB and CR dye onto MAC carbon followed D-R adsorption isotherm model.

(6) Sorption energy calculated from D-R isotherm suggested physical adsorption process for RB and CR respectively.

(7) The thermodynamic study indicated the adsorption process was spontaneous, exothermic in nature.

(8) FT-IR spectrophotometer studies indicated the functional groups such as surface $\mathrm{O}-\mathrm{H}, \mathrm{C}=\mathrm{O}, \mathrm{C}=\mathrm{C}, \mathrm{C}=\mathrm{CH}_{2}$ groups were responsible for dye binding on MAC.

(9) The surface area of MAC carbon was found to be $22.43 \mathrm{~m}^{2} / \mathrm{g}$. XRD studies revealed that MAC was amorphous material.

\section{References}

[1]. A.S Alzaydien, Adsorption of methylene blue from aqueous solution onto a Low-cost Natural Jordanian Tripoli, Am.J. of Environ. Sci. 5, 2009, 197-208.

[2]. B. Noroozi, G.A. Sorial, H. Bahrami, M. Arami, Equilibriums and kinetic adsorption study of cationic dye by a natural adsorbentsilkworm pupa, J.Hazard.Mater B, 139, 2007, 167- 174.

[3]. M.A.M. Salleh, D.K. Mahmoud, W.A.W.A. Karim, A. Idris, Cationic and anionic dye adsorption by agricultural solid wastes: A comprehensive review, Desalination, 280, 2011, 1-13.

[4]. S. Dawood, T.K. Sen, Removal of anionic dye Congo red from aqueous solution by raw pine and acid-treated pine cone powder as adsorbent: Equilibrium, thermodynamic, kinetics mechanism and process design, Water Res. 46, 2012, $1933-1946$.

[5]. S. Chatterjee, B.P. Chatterjee, A.K. Guha, Adsorptive removal of Congo red, a carcinogenic textile dye by chitosan, hydrobeads: Binding mechanism, equilibrium and kinetics, Colloid Surf A: Physiochem. 299, 2007, 146-152.

[6]. S.Arivoli, M. Thenkuzhali, Adsorption of Rhodamine B by acid activated carbon- kinetic, thermodynamic and equilibrium', Orbital, 2, 2009, 138-155,

[7]. M.N. Abbasi, R. Asl, Sonochemical degradation of Basic Blue 41 dye assisted by nanoTiO $\mathrm{O}_{2}$ and $\mathrm{H}_{2} \mathrm{O}_{2}, \mathrm{~J} . \mathrm{Hazard} \mathrm{Mater}$ 153, 2008, 942-947.

[8]. V.K. Gupta, A. Mittal, R. Jain, M. Mathur, S. Sikarwar, Photochemical degradation of hazardous dye- Safaranin-T using TiO 2 catalyst, J. Colloid. Interface Sci. 309, 2007, 460-465.

[9]. L. Fan, Y. Zhou, W. Yang, G. Chen, F. Yang, Electrochemical degradation of aqueous solution of Amaranth azo dye on ACF under potentiostatic model, Dyes Pigments, 76, 2008, 440-446.

[10]. M.H. Zonoozi, M.R.A. Moghaddam, M. Arami, Coagulation/Flocculation of dye containing solutions using Polyaluminium chloride and alum, Water Sci. Technol. 59, 2009, 1343-1351.

[11]. S. Sachdeva, A. Kumar, Preparation of nonporous composite carbon membrane for separation of Rhodamine B dye, J. Membr. Sci. 329, 2009, 2-10.

[12]. I.A.W. Tan, A.L. Ahmad, B.H. Hameed, and Adsorption of basic dye on high surface area activated carbon prepared from coconut husk: equilibrium, kinetic and hermodynamic studies, J. Hazard. Mater. 154, 2008, 337-346.

[13]. P.K. Malik, S.K. Saha, Oxidation of direct dyes with hydrogen peroxide using ferrous ion as catalyst, Sep. Purif. Technol. 31, 2003, 241-250.

[14]. A. Bhatnagar, M. Sillanppa, Utilization of agro- industrial and municipal waste materials as potential adsorbents for water treatment a review, Chem. Eng. J. 157, 2010, 277-296. 
[15]. M. Koroki, S. Saito, H. Hashimoto, T. Yamada, and M. Aoyama, Removal of Cr(VI) from aqueous solutions by the slum of bamboo grass treated with concentrated sulfuric acid, Environ.Chem.Lett, vol.8, no.1, pp. 59-61, 2010.

[16]. Q. Sun and L. Yang, The adsorption of basic dyes from aqueous solution on modified peat-resin particle, Water Res. 37(7), 2003, $1535-1544$,

[17]. K.V. Kumar and K. Porkodi, Batch absorber design for different solution volume/adsorbent mass ratios using the experimental equilibrium data with fixed solution volume/adsorbent mass ratio of malachite green onto orange peel, Dyes and Pigments, vol.74, no.3, 2007, 590-594.

[18]. R. Gong, Y. Sun, J. Chen, H. Liu, and C. Yang, Effect of chemical modification on dye adsorption capacity of peanut hull, Dyes and Pigments, vol. 67, no.3,2005, 175-181.

[19]. Sumanjit and N. Prasad, Adsorption of dyes on Rice Husk Ash, Indian journal of Chemistry-section A, vol.40, no.4,2001, 388-391.

[20]. R. K. Sumanjit, S. Mahajan, T.P.S. Rani, Walia, and R. Kaur, Adsorptive removal of five acid dyes using various unconventional adsorbents, Journal of Surface Science and Technology, vol.26, no.1-2, 2010,77-93.

[21]. J.W. Ma, H. Wang, F.Y. Wang, and Z.H. Huang, Adsorption of 2,4-dichlorophenol from aqueous solution by a new low-cost adsorbent-activated bamboo charcoal, Sep. Sci. Technol. 45,no.16,2010, 2329-2336.

[22]. S.Jai, R.V. Jayaram, Adsorption of phenol and substituted chlorophenols from aqueous solution by activated carbon prepared from jackfruit (artocarpus heterophyllus) peel- kinetics and equilibrium studies, Sep. Sci. Techn. 42, no.9, 2007, $2019-2032$.

[23]. P. Vijayalakshmi, V.S.S. Bala, K.V. Thiruvengadaravi, P. Panneerselvam, M. Palanichamy, and S. Sivanesan, Removal of acid violet 17 from aqueous solutions by adsorption onto activated carbon prepared from pistachio nut shell, Sep. Sci.Techn. 46, no.1, 2011, 155-163.

[24]. Z. Belala, M. Jeguirium, M. Belhachemi, F. Addoun, and G. Trouve, Biosorption of copper from aqueous solutions by data stones and palm-trees waste, Environ. Chem. Lett.. 9, no.1,2011, 65-69.

[25]. R. Rajesh Kannan, M. Rajasimman, N. Rajamohan and B. Sivaprakash, Equilibrium and Kinetic Studies on Sorption of Malachite Green using Hydrilla verticillata Biomass, Int. J. Environ. Res, 4, no. 4,2010, 817-824.

[26]. Y. Guo, and D.A. Rockstraw, Physicochemical properties of carbons prepared from pecan shell by phosphoric acid activation, Bioresour. Technol. 98,2007, 513-521.

[27]. A.A. Ahmad, B.H. Hameed, A.L. Ahmad, Removal of disperse dye from aqueous solution using waste-derived activated carbon: Optimization study, J. Hazard. Mater. 70, 2009, 612-619.

[28]. R. Akkaya, U. Ulusoy, Adsorptive features of chitosan entrapped in polyacrylamide hydrogel for $\mathrm{pb}^{2+}$, $\mathrm{UO}_{2}{ }^{2+}$, and $\mathrm{Th}^{4+}$, $\mathrm{J} \mathrm{Hazard}$ Mater. 151, 380-388.

[29]. G. Mckay, M. El Geundi and M. Nassar, Equilibrium studies during the removal of dyestuffs from aqueous solutions using bagasse pith, Water Res. 21, no.12,1987, 1513-1520.

[30]. G. Limousin, J.P. Gaudet, L. Charlet, S. Szenknect, V. Barthes, M. Krimissa, Sorption isotherms: a review on physical bases, modeling and measurement, Applied Geochemistry, 22, 2007, 249-275.

[31]. H.M.H. Gad, A.A. El-Sayed, Activated carbon from agricultural by products for the removal of Rhodamine-B from aqueous solution, J. Hazard. Mater. 168, 2009,1070-1081.

[32]. A.H. Chen, S.C.Liu, C.Y. Chen and C.Y. Chen, Comparative adsorption of $\mathrm{Cu}(\mathrm{II}), \mathrm{Zn}$ (II) and $\mathrm{Pb}$ (II) ions in aqueous solution on the crosslinked chitosan with epichlorohydrin, J. Hazard. Mater. 154, 2008, 184-191.

[33]. S. Chowdhury and P. Saha, Sea shell powder as a new adsorbent to remove Basic Green 4 (Malachite Green) from aqueous solutions: Equilibrium, kinetic and thermodynamic studies, Chemical Engineering Journal, 164, 168-177.

[34]. D.S. Jovanoic, Physical adsorption of gases I: Isotherms for monolayer and multilayer adsorption. Colloid. Poly. Sci. 235, 1969, 1203-1214.

[35]. S. Eftekhari, A. Habibi-Yangjeh, S. Sohrabnezhad, Application of AlMCM-41 for competitive adsorption of methylene blue and Rhodamine B: Thermodynamic and kinetic studies, J. Hazard. Mater. 178,2010, 349-355.

[36]. D. Sun, X. Zhang, Y. Wu, X. Liu, Adsorption of anionic dyes from aqueous solution on flyash, J. Hazard. Mater. 181,2010, 335342 .

[37]. H. Lata, V. Garg. R. Gupta, “Adsorptive removal of a basic dye by chemically activated parthenium biomass: Equilibrium and Kinetic modeling,', Desalination. 219, 2008, 250-261.

[38]. W. Weber, J. Morris, Kinetics of adsorption on carbon from solution. J. Sanit Eng Div Am Soc Civ Eng, 89, 1963, 31-60.

[39]. O. Yavuz, Y. Altunkaynak, F. Guzel, Removal of copper, nickel, cobalt and manganese from aqueous solution by kaolinite, Water Res. 37, 2003, 948-952.

[40]. M.C. Somasekhara Reddy, L. Sivaramakrishna, A. Varada Reddy, The use of an agricultural waste material, Jujuba seeds for the removal of anionic dye (Congo red) from aqueous medium, J. Hazard. Mater. 203-204,2012, 118-127. 